\title{
Patchwork plagiarism - a jigsaw of stolen puzzle pieces
}

\author{
Vesna Šupak Smolčić ${ }^{*}$, Lidija Bilić-Zulle1,2 \\ ${ }^{1}$ Clinical Institute of Laboratory Diagnostics, Rijeka Clinical Hospital Center, Rijeka, Croatia \\ 2Department of Medical Informatics, Rijeka University School of Medicine, Rijeka, Croatia \\ *Corresponding author: vesnasupak@gmail.com
}

\begin{abstract}
Plagiarism remains at the top in terms of interest to the scientific community. In its many vicious forms, patchwork plagiarism is characterized by numerous unresolved issues and often passes "below the radar" of editors and reviewers. The problem of detecting the complexity of misconduct has been partially resolved by plagiarism detection software. However, interpretation of relevant reports is not always obvious or easy. This article deals with plagiarism in general and patchwork plagiarism in particular, as well as related problems that editors must deal with to maintain the integrity of scientific journals.
\end{abstract}

Key words: plagiarism; patchwork plagiarism; scientific misconduct; publication ethics

\section{Introduction}

The issue of plagiarism is arousing increased interest within the scientific community. As one of the three most prominent forms of scientific misconduct, plagiarism, together with falsification and fabrication, is a major problem, especially for small developing journals such as Biochemia Medica (1). Because we are guided by the dedication to promote research integrity in our journal and because we have received several submissions containing plagiarized text, we feel that it is prudent to warn all authors and our readers about this impermissible misconduct. Scientists, as authors of scientific knowledge, are regarded as people with high ethical and moral standards; therefore, they should be aware that any form of plagiarism is a serious offense of scientific integrity that will not be tolerated.

By its definition, plagiarism is "unauthorized appropriation of another's work, ideas, methods, results, or words without acknowledging the source and original author" (2). Plagiarism takes on many forms: blatant plagiarism, self-plagiarism, technical plagiarism, patchwork plagiarism, etc (3). All of these forms are taken into consideration when protecting the research integrity of a particular journal and the scientific community.

\section{Temptation to engage in patchwork writing}

Scientific writing is probably the most demanding aspect of scientific work. Synthesizing knowledge of a particular area in the context of one's own research and critically discussing results are not easy tasks. An author must present his or her work uniquely; however, he or she must adhere always to the well-established principles of scientific methodology and research integrity. Regardless of insecurity about one's writing skills, the best way to write a scientific paper is to use one's own words without the "assistance" of other literature. That does not imply, however, that an author is to avoid 
reading and using literature while writing. In fact, authors should study all available references and use known facts (but not sentences written by other authors) in the synthesis of original work. However, incorporating sentences verbatim from other manuscripts, which may seem convenient and state "just what I meant," is never a good choice. It is never permissible to take whole sentences or any of their parts and portray them as original work for any form of scientific writing. Scientific authors should be especially careful when writing review articles, which are free-form summaries of particular subjects for which the authors choose relevant literature sources (4). An author's greatest contribution in review articles is relating his or her proper intellectual and scientific involvement in the synthesis and presentation of relevant data. Pressure to publicize, short deadlines, and inexperience can lead to the creation of a mosaic of excerpts from published articles that must be considered intellectual fraud. Consequently, review articles are no longer popular with numerous journals, even though they have great educational value. Systematic reviews are preferred because they are prepared according to strict guidelines in which all steps of scientific research, from the literature search to the presentation of summarized data, must be defined. Systematic reviews summarize scientifically accessed data and provide recommendations for best practices. Biochemia Medica welcomes review articles in their traditional form and systematic reviews as well; however, the journal's editors have no tolerance for mosaics, patchworks, jigsaws, or any kinds of manuscripts constructed from stolen words.

\section{Tools and policies}

Although techniques and software for detecting plagiarism are rapidly improving, some constraints still exist. Patchwork plagiarism (i.e., patch writing or mosaic writing) is one such constraint; it is defined as taking text portions from several different sources, combining them, and presenting the resulting text as one's own work (5). As opposed to other forms of plagiarism that can be detected using plagiarism detection software, patchwork pla- giarism is much harder to identify because of its complexity. Plagiarism detection software enables users to compare suspect manuscripts with published materials. As a result, the software provides a percentage of similarity between two (or more) manuscripts. The widely accepted threshold for plagiarism is a $10 \%$ similarity rate between texts (3). Analytical interpretation is simple when there are only one or two sources from which text was inappropriately taken. Small portions of copied text from several sources may be detected with plagiarism software, but individual similarity rates may be only $2-3 \%$ even though the sum of all percentages may exceed $10 \%$. Thus, patchwork plagiarism sometimes passes "below the radar" of plagiarism detection software, and software analysis must always be manually checked and carefully interpreted $(3,6)$.

Journal editors and reviewers usually become suspicious of patchwork plagiarism based on experience or obscure feelings of déjà vu. The common patterns are the appearance of "brilliant" sentences in manuscripts that require major modifications or complex, well-written English sentences in manuscripts that are otherwise poorly written. These findings usually trigger further analysis. Poor knowledge of the English language is the most common excuse for plagiarism from non-native English speakers (5). While scientists do not have difficulty creating intellectually demanding concepts for research presentations, they may have difficulty presenting their research in a non-native language; therefore, they sometimes "help" themselves by copying phrases from several sources. Several useful online language editing services help authors by offering proofreading services so that their manuscripts can be reviewed by professional language editors. The editors of Biochemia Medica do not prefer any particular editing service to another, and they provide some useful links on the journal's web page.

To establish responsible editorial practices, it is not enough to rely on suspicions; rather, strict journal policies for checking manuscripts and dealing with revealed plagiarism must be defined. Biochemia Medica recently introduced a Research integrity editor and embraced the highest standard for 
publication practices according to the Committee on Publication Ethics (COPE) (7). All submitted manuscripts that are sent out for external peer review are screened using CrossCheck plagiarism detection software. Cases of detected plagiarism will be processed according to COPE's recommendations; thus, authors will be warned and their institutions will be informed, depending on the severity of misconduct (8). This information is usually not well accepted and the accused author often feels attacked and offended. It is not unusual for the individual to become defensive in an aggressive way. Excuses often vary, but authors usually deny knowing of such fraud and think that citing a

\section{References}

1. Martyn C. Fabrication, falsification and plagiarism. Q J Med 2003;96:243-4. http://dx.doi.org/10.1093/qjmed/hcg036.

2. Roig M. Avoiding plagiarism, self-plagiarism, and other questionable writing practices: A guide to ethical writing. Office of Research Integrity, updated Sep 29 2011. Available from: http://ori.hhs.gov/avoiding-plagiarism-self-plagiarism-and-other-questionable-writing-practices-guide-ethical-writing. Accessed November 20, 2012.

3. Bazdaric K, Bilic-Zulle L, Brumini G, Petrovecki M. Prevalence of plagiarism in recent submission to the Croatian medical journal. Sci Eng Ethics 2012;18:223-9. http://dx.doi. org/10.1007/s11948-011-9347-2.

4. Rosen MR. Plagiarism in the Medical/Scientific literature. J Cardiovasc Pharmacol 2010;56:709. http://dx.doi. org/10.1097/FJC.0b013e3182004ee2. copied manuscript through references justifies their actions. Therefore, proper education regarding methodologies of scientific work and research integrity is needed from the very beginning of professional training. Awareness of plagiarism detection systems and journal prohibitions against plagiarism in any form should deter authors from misconduct. This anti-plagiarism emphasis will provide a basis for creating a professional and cultural environment that acknowledges only the highest standards of research ethics.

\section{Potential conflict of interest}

None declared.

5. Roig M. Plagiarism and self-plagiarism: What every author should know. Biochem Med 2010;20:295-300.

6. Wager E. How should editors respond to plagiarism? COPE discussion paper. 2011. Available from: http://publicationethics.org/resources/discussion-documents. Accessed November 20, 2012.

7. Simundic AM. Biochemia Medica appoints Research integrity editor. Biochem Med 2012;22:271.

8. Committee on Publication Ethics. Flowchart: What to do if you suspect plagiarism (Suspected plagiarism in a submitted manuscript). Available at: http://publicationethics. org/resources/flowcharts. Accessed December 19, 2012. 